Archive for

Organic Chemistry

Arkivoc 2020, part ii, $134-145$

\title{
Evaluation of protonation sites in two MacMillan catalysts in solution by gas phase predissociation spectroscopy and electronic structure calculations
}

\author{
Laís C. Tavares, ${ }^{\mathrm{a}}$ Tatiana C. Penna, ${ }^{\mathrm{a}}$ Mark Johnson, ${ }^{\mathrm{b}}{ }^{\mathrm{a}}$ and Thiago C. Correra ${ }^{\mathrm{a} *}$ \\ ${ }^{a}$ Department of Fundamental Chemistry, Institute of Chemistry, University of São Paulo, \\ Av. Prof. Lineu Prestes, 748, 05508-000, São Paulo, SP, Brazil \\ ${ }^{b}$ Sterling Chemistry Laboratory, Yale University, \\ P. O. Box 208107, New Haven, Connecticut 06520, United States \\ Email: mark.johnson@yale.edu,tcorrera@iq.usp.br
}

In honor of Prof. José Manuel Riveros on the occasion of his $80^{\text {th }}$ anniversary

Received 01-06-2020

Accepted 05-11-2020

Published on line $05-18-2020$

\begin{abstract}
The protonation sites of first and second generation MacMillan catalyst were evaluated using cryogenic ion vibrational predissociation spectroscopy. The comparison with calculated spectra showed that when isolated in the gas phase, the species are protonated at the secondary amine, as would be expected by the difference in free energy of the calculated protomers. The relative energies of the conformers were also calculated for the species in solution using the SMD model, in water, methanol and in a 1:1 (v/v) water:methanol mixture. This comparison indicates that the trends observed in the gas phase are retained in solution, and that the secondary amine is the protonation site regardless the solvent used.
\end{abstract}

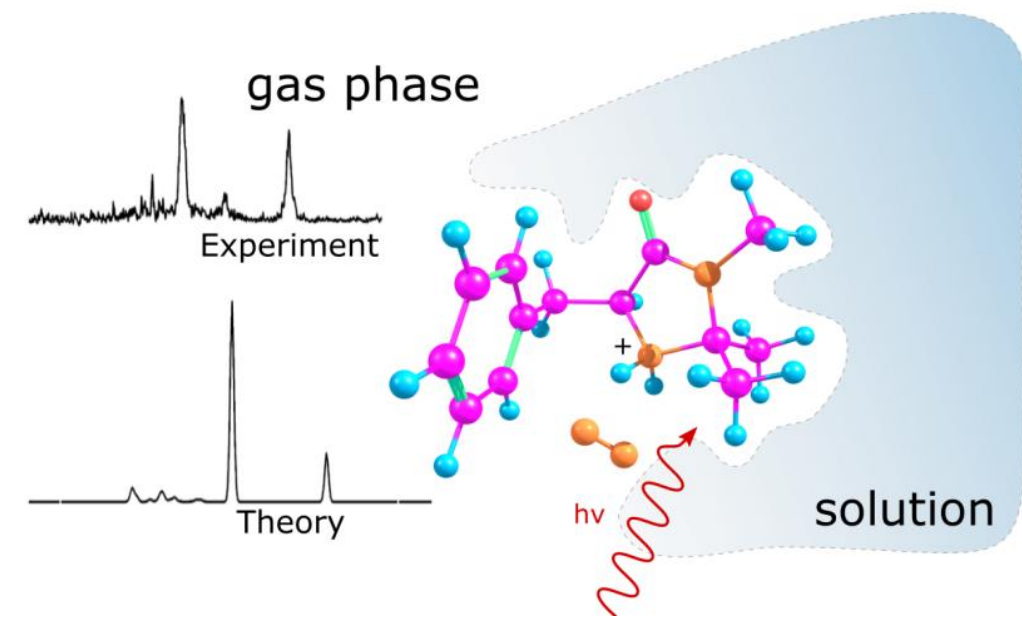

Keywords: Organocatalysis, predissociation spectroscopy, MacMillan catalyst, DFT calculations. 


\section{Introduction}

New challenges posed by the modern world have been pushing the boundaries of Science in general and Chemistry in particular because of its central role. ${ }^{1}$ Advances in diverse fields ranging from nanostructured materials, renewable energy and feedstock to new drugs and treatments are a few examples where transformational change is currently underway. ${ }^{2}$ In this context, Chemistry plays a fundamental role by providing insights into the pathways that drive chemical processes at the molecular level, thus enabling the understanding and development of new processes. Paramount among these processes is the catalytic activation and transformation of chemical bonds. ${ }^{3,4}$ It is estimated that roughly 85 to $90 \%$ of the products generated by chemical industry relies on catalysts at least in one step along the reaction sequence. ${ }^{5}$ Asymmetric catalysts are especially important because the absolute configuration of enantiomeric centers are essential for the pharmaceutical industries. ${ }^{6,7}$ About twenty years ago, a new class of organocatalysts capable of carrying out chiral synthesis opened a new era in the field. ${ }^{8-12}$ The use of small organic molecules made it possible to obtain outstanding enantiomeric excess with high reaction yield, while having with much less impact on the environment than previous metal-based strategies due to their lower toxicity to living organisms. ${ }^{13}$ Moreover, these "green" organocatalysts promise to use reactants more efficiently as well as lower costs associated with purification and disposal.

Here we are concerned with the class of organocatalysts based on the imidazolidinones, also known as the MacMillan catalysts, ${ }^{14-18}$ with two structures illustrated in Figure 1. These compounds have been shown to be active in a series of chiral transformations with high yields and enantiomeric excess, including FriedelCrafts, Diels Alder and Mukaiyama-Michael reactions, to name a few. ${ }^{19-25}$ Because these reactions are usually carried out under acidic conditions, it is important to establish the intrinsic protonation sites of these catalysts in solution, as the protonation equilibrium could disturb the nature of the catalytic species. ${ }^{26-29}$ One way to monitor the structures of ionic species in solution is to extract them into a mass spectrometer using ambient ionization, where a highly refined arsenal of tools are available to identify structures. In this case, however, despite the great sensitivity and dynamic detection range of this technique, traditional mass spectrometry methods are not capable of differentiating conformers and protomers. ${ }^{30-32}$ In the past decade, nonetheless, hybrid methods that combine mass spectrometry with cryogenic ion vibrational spectroscopy have been developed that are capable of structure determination. ${ }^{33,34}$ In that approach, vibrational spectra are obtained for ions that are cooled after they are extracted from solution to cryogenic temperatures. Once cold ( 20K), weakly bound neutral species such as $\mathrm{H}_{2}$ or $\mathrm{N}_{2}$ are condensed onto the ions. These adducts or "mass tags" are then photodissociated upon resonant absorption of a single photon from a tunable IR laser. Measurement of the photodissociation yield of the tagged species as a function of the laser wavelength yields the linear vibrational spectra of the mass selected ions in the gas phase. By comparing the experimental band pattern with theoretical calculations for candidate structures of the protonated imidazolidinones, it is possible to establish their protonation sites and thus infer the speciation of these catalysts in solution. ${ }^{30,35,36}$

In this work, we evaluated the protonation sites of two imidazolidinones known as the first and second generation MacMillan catalysts with structures indicated in Figure 1.

The cations of both neutral compounds corresponding to addition of a proton from solution were extracted by electrospray (ESI) from a 1:1 methanol:water mixture, which is typically used as solvent for these species. Their structures were then interrogated by analyzing the pattern of vibrational bands obtained using cryogenic predissociation spectroscopy with DFT calculations as described below. To gauge whether the gas phase results obtained correlate with the solution phase, solvation effects were modeled by the SMD method, as suggested in the literature. ${ }^{37}$ 


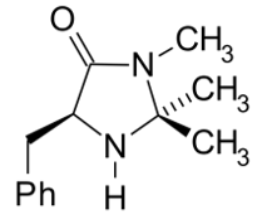

Cat1

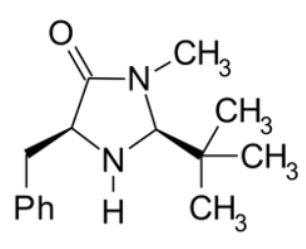

Cat2

Figure 1. First (left) and second (right) generation MacMillan catalyst structures.

\section{Results and Discussion}

Figure 2 presents the predissociation spectra of $[\mathrm{Cat} 1+\mathrm{H}]^{+}$and $[\mathrm{Cat} 2+\mathrm{H}]^{+}$compared with the calculated spectra of the same species with three different protonation sites: i) secondary amine; ii) amide oxygen and, iii) amide nitrogen, at the $B 3 L Y P / 6-311+G(3 d f, 2 p)$ level of theory. For both catalysts, the experimental spectra are dominated by mainly two vibrational features at the high frequency range (above $2000 \mathrm{~cm}^{-1}$ ) and a distinctive set of bands in the crowded fingerprint region below $1500 \mathrm{~cm}-1$. This preliminary observation suggests that, despite the change in structure between first and second generation MacMillan catalysts, the protonation site and/or conformation preferences are similar.

For $[\mathrm{Cat} 1+\mathrm{H}]^{+}$, the relative intensities and splitting between the two bands in the higher frequency range at 3286 and $3051 \mathrm{~cm}^{-1}$ (Table 1) suggest their assignment to the $\mathrm{NH}_{2}^{+}$asymmetric and symmetric stretching fundamentals, respectively. This pattern is in best agreement with the theoretical results obtained for the secondary amine protonation, whose scaled vibrational frequencies were calculated at 3369 and $3160 \mathrm{~cm}^{-1}$, respectively. The calculated spectra of the carbonyl protonated ( $4.6 \mathrm{kcal} \mathrm{mol}^{-1}$ higher in energy) and the amide protonated species (18.2 $\mathrm{kcal} \mathrm{mol}^{-1}$ higher in energy), on the other hand, are in poor agreement, most noticeably in that they completely miss the strong band at $3051 \mathrm{~cm}^{-1}$ observed experimentally. (See Table S1 in Supplementary Information). Moreover, the theoretical spectrum of the isomer protonated at the secondary amine nicely accounts for the pattern of observed bands in the lower frequency region, matching particularly well the carbonyl stretch, (calculated at $1753 \mathrm{~cm}^{-1}$ vs the experimental value of $1770 \mathrm{~cm}^{-1}$ ). On the other hand, the $\mathrm{C}=\mathrm{O}$ fundamentals for the carbonyl and amide protonated species are almost $100 \mathrm{~cm}^{-1}$ lower and higher in energy with values of 1684 and $1866 \mathrm{~cm}^{-1}$, respectively, after the same scaling.

The remaining features of the fingerprint region are less definitive. The highest energy amide protonated species show the poorest match in this region, while the other two protomers show a similar profile, with predicted bands red or blueshifted from the experimental bands at 1394 and $1370 \mathrm{~cm}^{-1}$, assigned to multiple $\mathrm{C}-\mathrm{H}$ bending motions.

The spectrum of the second generation catalyst [Cat $2+\mathrm{H}]^{+}$(Figure 2 bottom) is similar to that observed for $[\mathrm{Cat} 1+\mathrm{H}]^{+}$. Once again, the calculated $\mathrm{NH}_{2}^{+}$bands of the isomer protonated at the secondary amine best recover the relative intensities and splitting of the strong features observed in this frequency range, (3290 and $3057 \mathrm{~cm}^{-1}$ ) but are significantly blueshifted with bands predicted at 3383 and $3175 \mathrm{~cm}^{-1},($ Table 1). The carbonyl stretch predicted for this lowest energy structure $\left(1756 \mathrm{~cm}^{-1}\right)$ is also in better agreement with the experimental band at $1770 \mathrm{~cm}^{-1}$, while the calculated $\mathrm{C}=\mathrm{O}$ fundamentals of the other protomers do not recover the observed location of this feature (Table S1 in Supporting Information). 

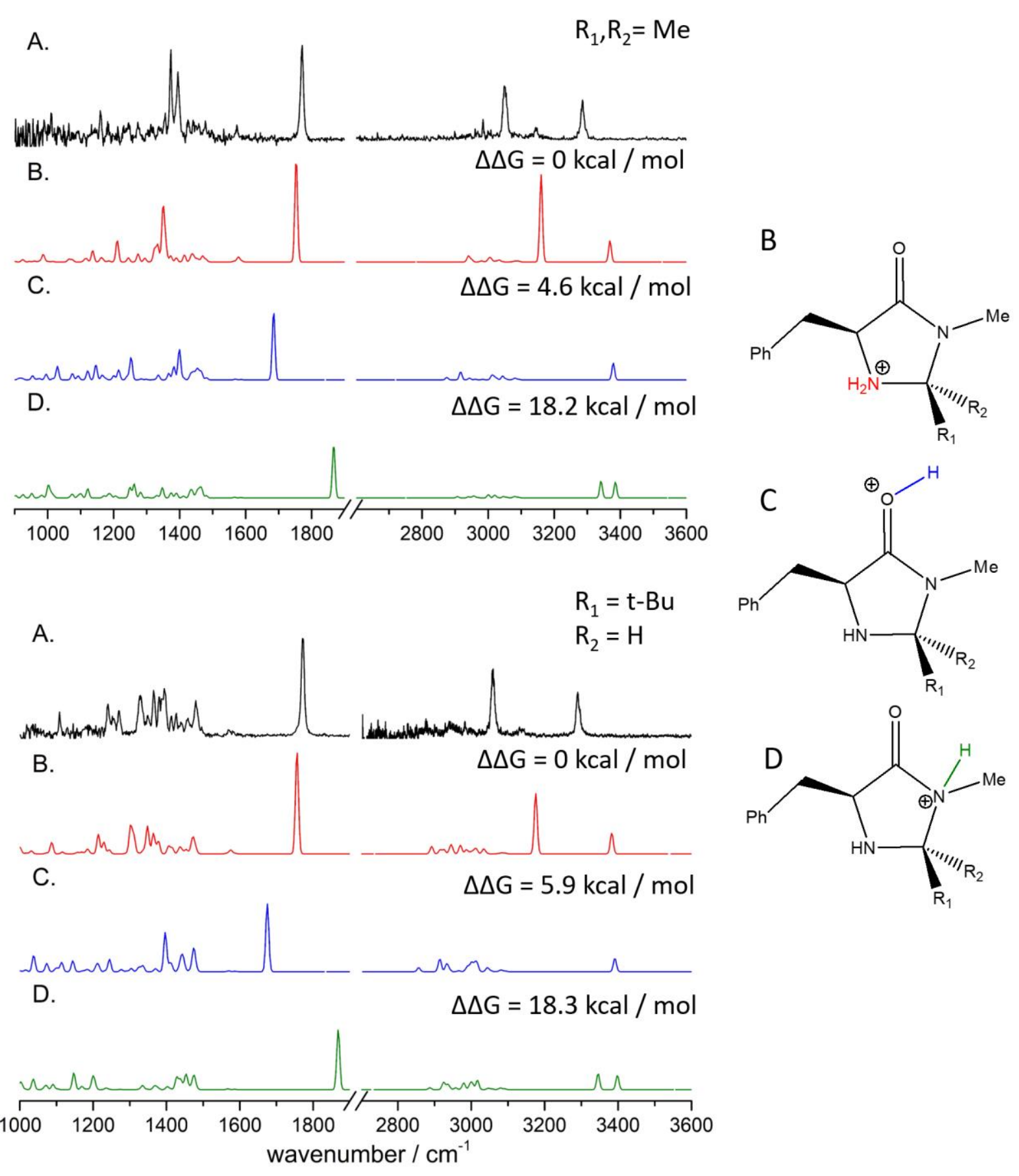

Figure 2. Top: first generation $[\mathrm{Cat} 1+H]+(R 1, R 2=M e)$ and bottom: second generation $[\mathrm{Cat} 2+\mathrm{H}]+(\mathrm{R} 1=\mathrm{t}-\mathrm{But}$; $\mathrm{R} 2=\mathrm{H})$ MacMillan organocatalysts. A) Experimental vibrational pre-dissociation spectra of the N2-tagged species. Theoretical vibrational spectra of the catalyst with different protonation sites at B3LYP/6$311+G(3 d f, 2 p)$ level of theory: (B) secondary amine; (C) amide oxygen; (D) amide nitrogen.

In summary, the theoretical analysis of the spectra strongly support the identification of the protonated secondary amine structures as the isomeric forms generated for both the Cat1 and Cat2 in an ESI ambient ion source. 
Table 1. Comparison of the main observed vibrational features (Exp.) in $\mathrm{cm}^{-1}$ of $[\mathrm{Cat} 1+\mathrm{H}]^{+}$and $[\mathrm{Cat} 2+\mathrm{H}]^{+}$with the lowest energy protomer calculated at the B3LYP/6-311+G(3df,2p), \{CAM-B3LYP/6-311+G(3df,2p)\} and $[\mathrm{M} 06-2 \mathrm{X} / 6-311+\mathrm{G}(3 \mathrm{df}, 2 \mathrm{p})]$ levels of theory

\begin{tabular}{|c|c|c|c|c|}
\hline \multirow[b]{2}{*}{ Mode assignment } & \multicolumn{2}{|r|}{$[\text { Cat } 1+\mathrm{H}]^{+}$} & \multicolumn{2}{|c|}{$[\text { Cat2+H }]^{+}$} \\
\hline & Exp. & B3LYP $\{C A M\}[M 06]$ & Exp. & B3LYP $\{C A M\}[M 06]$ \\
\hline $\mathrm{NH} 2$ asymmetric stretch & 3286 & $3369\{3324\}[3324]$ & 3290 & $3383\{3338\}[3352]$ \\
\hline NH2 symmetric stretch & 3051 & $3160\{3123\}[3144]$ & 3057 & $3175\{3135\}[3141]$ \\
\hline Carbonyl stretch & 1770 & $1753\{1754\}[1776]$ & 1770 & $1756\{1756\}$ [1779] \\
\hline NH2 bending & 1571 & $1577\{1553\}$ [1539] & 1568 & $1575\{1551\}[1542]$ \\
\hline \multirow[t]{2}{*}{ Multiple $\mathrm{CH}$ bending } & 1394 & $1350\{1362\}[1373]$ & & \\
\hline & 1370 & $1334\{1339\}[1344]$ & & \\
\hline $\mathrm{CH}$ bending & & & $1315-1500$ & $1290-1490$ \\
\hline C-N stretches & & & $1240-1280$ & $1200-1240$ \\
\hline
\end{tabular}

It is worth noting that, at the B3LYP/6-311+G(3df,2p) level of theory, for both $[\mathrm{Cat} 1+\mathrm{H}]^{+}$and $[\mathrm{Cat} 2+\mathrm{H}]^{+}$, although the scaled low frequency bands values are in good agreement with the observed bands, the higher frequency modes are still ca. $100 \mathrm{~cm}^{-1}$ blueshifted relative to the experimental values. We note, however, that these modes involve acidic protons that are typically much more anharmonic than the skeletal modes and $\mathrm{NH}$ bends. This, in turn, suggests the necessity of the use of dual scale factors, as suggested for calculations carried out with more limited basis sets. ${ }^{38}$

To compare the effect of different methodologies on the predicted vibrational spectra, the most stable protomer (secondary amine protonation) was also calculated in CAM-B3LYP and M06-2X functionals, as suggested in previous works of our group ${ }^{37,39}$ (Table 1), maintaining the same basis set. The use of these functionals led to similar improvements in the calculated spectra for both catalysts (Table 1). In the high frequency bands, the calculated bands were redshifted, reducing the observed shift for B3LYP from approximately $90 \mathrm{~cm}^{-1}$ to $45 \mathrm{~cm}^{-1}$ for the asymmetric $\mathrm{NH}_{2}$ stretching mode. For the symmetric stretch, the improvement was a little less pronounced as the shift was reduced from approximately 115 to $80 \mathrm{~cm}^{-1}$ (see Figure S1 in the Supporting Information and Table 1). In the lower frequency range, the CAM-B3LYP functional led to no difference on the carbonyl stretching mode when compared to B3LYP functional. For M06-2X, however, the calculated frequency is blueshifted, but only by 6 and $9 \mathrm{~cm}-1$ from the experimental values for $[\mathrm{Cat} 1+\mathrm{H}]+$ and $[\mathrm{Cat} 2+\mathrm{H}]+$ respectively. It is also worth noting that for $[\mathrm{Cat} 1+\mathrm{H}]^{+}$, the intensity of the features observed for the bands 1394 and $1370 \mathrm{~cm}^{-1}$ were better represented by the CAM-B3LYP and M06-2X functionals, despite of the blueshift in the frequency values.

For both catalysts studied, the secondary amine structure is calculated to be the most stable among the candidate protomers $(\Delta \Delta \mathrm{G}=0 \mathrm{kcal} / \mathrm{mol})$. The formation of the protonated species at the secondary amine would also be expected considering the basicity of the functional groups in this species. If the protonation at the amide would occur, for example, it would be preferable to do so at the oxygen atom ( $\Delta \Delta \mathrm{G}=4.6$ or 5.9 $\mathrm{kcal} / \mathrm{mol}$, for $[\mathrm{Cat} 1+\mathrm{H}]^{+}$and $[\mathrm{Cat} 2+\mathrm{H}]^{+}$, respectively) given that the lone pair of the amide nitrogen is less basic, with it being resonance-stabilized in this structure. For that reason, these protomers have a higher free energy $\left(\Delta \Delta \mathrm{G}=18.2\right.$ and $18.3 \mathrm{kcal} / \mathrm{mol}$ for $[\mathrm{Cat} 1+\mathrm{H}]^{+}$and $[\mathrm{Cat} 2+\mathrm{H}]^{+}$, respectively) and are therefore not expected to be observed in the gas phase.

We recognize that, despite the ample evidence for the protonation site to be located at the secondary amine, the results discussed so far are carried out in the gas phase and indirectly probe the speciation of the 
cations in solution prior to extraction into the mass spectrometer by electrospray ionization (ESI). As described before in the literature, ESI ion source conditions and solvents used can promote isomerization of the species extracted, as extensively discussed for protonated $p$-aminobenzoic acid and other species. ${ }^{37,40-42}$

To evaluate if the results observed in the gas phase could be transferred to solution, we carried out the continuous solvation calculation using the SMD method in water, methanol and a methanol:water 1:1 mixture at the M06-2X/cc-pVDZ level of theory, as this is the preferred functionals for SMD calculations. The relative energy obtained for each catalyst in these different condensed phases are collected in Table 2.

Table 2. Relative free energy in $\mathrm{kcal} \mathrm{mol}^{-1}$ at $298 \mathrm{~K}$ for the protomers of $\left[\mathrm{Cat} 1+\mathrm{H}^{+}\right]$and $([\mathrm{Cat} 2+\mathrm{H}+]$ in parenthesis) in different solvents as calculated by the SMD solvation scheme at M06-2X/cc-pVDZ level of theory and gas phase results for B3LYP/6-311+(3df,2p) and M06-2X/cc-pVDZ for comparison

\begin{tabular}{|c|c|c|c|c|c|}
\hline \multirow[b]{2}{*}{$\mathrm{kcal} \mathrm{mol}^{-1}$} & \multicolumn{2}{|c|}{ Gas Phase } & \multicolumn{3}{|c|}{ SMD M06-2X/cc-pVDZ } \\
\hline & $\begin{array}{c}\text { B3LYP/ } \\
6-311+G(3 d f, 2 p)\end{array}$ & M06-2X/ cc-pVDZ & Methanol & Water & 1:1 Mixture ${ }^{a}$ \\
\hline Secondary amine & $0.0(0.0)$ & $0.0(0.0)$ & $0.0(0.0)$ & $0.0(0.0)$ & $0.0(0.0)$ \\
\hline Amide Oxygen & $4.6(5.9)$ & $4.2(5.5)$ & $10.5(10.6)$ & $9.0(9.8)$ & $9.3(10.4)$ \\
\hline Amide Nitrogen & $18.2(18.3)$ & $15.7(17.3)$ & $20.1(21.6)$ & $18.6(20.4)$ & $19.7(21.4)$ \\
\hline
\end{tabular}

a) Methanol:water 1:1 mixture in volume, 0.4:0.6 methanol:water molar fraction

These relative free energy values show that, for both catalysts and solution compositions, the same trend observed in the gas phase is predicted to be preserved in solution, with the secondary amine protonated protomer being more stable than the amide protonation at oxygen and nitrogen, respectively. In fact, when implicit solvation effects are considered, the relative free energy for the amide oxygen protonated protomer increases from approximately 5 to $10 \mathrm{kcal} \mathrm{mol}^{-1}$ when compared to gas-phase results, while the amide protonation relative energy increases from 2 to $4 \mathrm{kcal} \mathrm{mol}^{-1}$. This suggests that the protonated secondary amine is even more stabilized than the other protomers in solution, what is in line with what is expected for amine protonation trends from gas phase to solution. ${ }^{43}$ This trend is in agreement with the $\mathrm{pK}_{\mathrm{a}}$ values expected for the different protonation sites of imidazolidinones in water ${ }^{44,45}$ (Figure S2 in Supporting Information) and can be explained by the fact that the secondary amine charge is more localized than the charge in the other two protomers, which are likely more delocalized by the amide resonance. This hypothesis is supported by the NBO charge calculated at the B3LYP/6-31+G(d,p) level of theory for $[\mathrm{Cat} 1+\mathrm{H}]^{+}$and $[\mathrm{Cat} 2+\mathrm{H}]^{+}$, as shown in Figure 3. As can be seen, the secondary amide shows the lowest NBO charge in comparison to the other protonation sites. Therefore, the increased charge density in the secondary amine is better solvated than the other two protomers.

These results suggest that the protonation tendency observed in the gas phase may be transferred to solution, as the relative energy values of the calculated protomers are retained. ${ }^{37}$ 


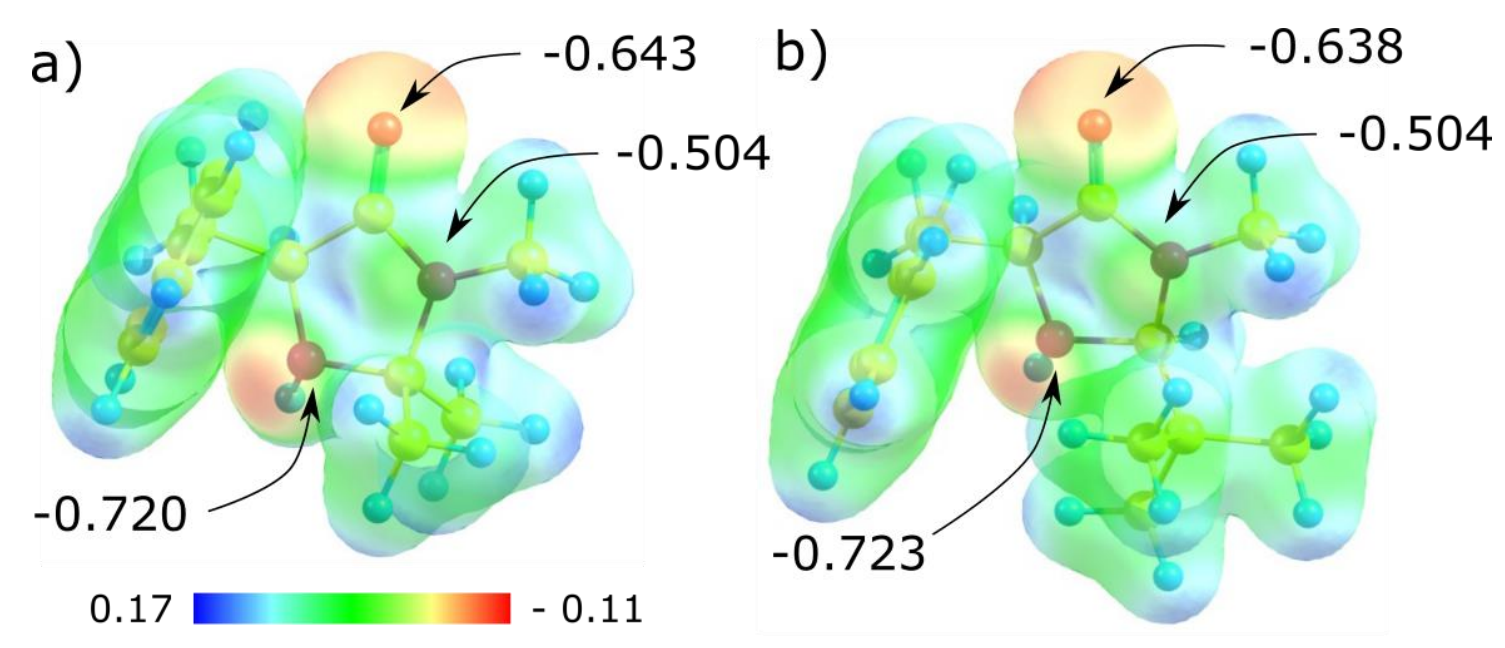

Figure 3. Representation of a) Cat1 and b) Cat2 NBOcharges at the protonation sites at the $B 3 L Y P / 6-31+G(d, p)$ level of theory overlaid to a molecular electrostatic potential surface mapped on a 0.013458 iso-surface value. $\mathrm{C}$ - yellow, $\mathrm{H}$ - blue, $\mathrm{N}$ - purple and $\mathrm{O}$ - red.

\section{Conclusions}

The MacMillan catalysts were evaluated using Predissociation Spectroscopy and showed that the protonation site for these species occurs at the secondary amine in the gas phase, for both catalyst generations. This species is also the most stable protomer by 4.6 and $5.9 \mathrm{kcal} \mathrm{mol}^{-1}$ for $\left[\mathrm{Cat} 1+\mathrm{H}^{+}\right]$and $\left[\mathrm{Cat} 2+\mathrm{H}^{+}\right]$, respectively.

The predicted absorptions at the B3LYP/6-311+(3df,2p) level of theory accurately reproduced the bands at the lower frequency region of the spectra but underestimated the red-shifts in the $\mathrm{NH}_{2}$ stretching bands in the highly anharmonic region above $3000 \mathrm{~cm}^{-1}$. This discrepancy was less significant, however, with calculations using the CAM-B3LYP and M06-2X functionals. Solvation effects were modeled by the SMD method and showed that for both catalysts, the energy trends observed in the gas phase are conserved in solution for water, methanol and water:methanol 1:1 mixture, as expected by comparison with $\mathrm{pK}_{\mathrm{a}}$ values in water for similar species. Therefore, we suggest that the protonation site characterized in the gas phase can be extrapolated to the situation in solution. These considerations indicate that the secondary amine is the preferential protonation site for the imidazolidinones, and the preference for this arrangement can be rationalized due to the amide resonance that reduces the amide basicity and charge density, thus stabilizing the secondary amine protonation site in the gas phase and in solution.

\section{Experimental Section}

All chemicals were purchased from Sigma Aldrich, and each of the organocatalysts Cat1 ((5S)-(-)-2,2,3Trimethyl-5-benzyl-4-imidazolidinone monohydrochloride) and Cat2 ((2S,5S)-(-)-2-tert-Butyl-3-methyl-5benzyl-4-imidazolidinone) were dissolved in a 1:1 methanol:acetic acid solution to a final concentration of $10^{-3} \mathrm{M}$. The ions were extracted from solution by electrospray ionization (ESI) and guided through the Yale Tandem Photofragmentation Mass Spectrometer, described in detail elsewhere. ${ }^{46,47}$ The ionized species pass through differential pumping stages composed of ion guides and skimmers until they reach the ion trap where they were collisionaly cooled down to $60 \mathrm{~K}$ by a helium buffer gas containing a small fraction of nitrogen gas. 
At this temperature, the ions are "tagged" with molecular nitrogen, forming an adduct that is mass selected and probed by infrared predissociation spectroscopy. An OPO/OPA parametric system (Laservision) was used to dissociate the tagged ions in a range from $1000 \mathrm{~cm}^{-1}$ to $3600 \mathrm{~cm}^{-1}$. The photodissociation yield as a function of the laser wavelength provides de vibrational spectrum of the ion.

Experimental results were compared to electronic structure and vibrational spectrum calculations carried out at the Gaussian09 computational package. ${ }^{48}$ All reported species were confirmed to be true minima by displaying no imaginary frequency upon vibrational analysis. DFT was used to describe the electronic structure, and different functionals, B3LYP, ${ }^{49}$ CAM-B3LYP ${ }^{50}$ and M06-2X ${ }^{51}$ were tested with the same basis set, $6-311+G(3 d f, 2 p)$. Scaling factors were used to correct the vibrational frequencies due to anharmonicity effects. The theoretical spectra were scaled by 0.967, 0.947, 0.952 at B3LYP, CAM-B3LYP and M06-2X, respectively. ${ }^{52}$ NBO charges were calculated at the $B 3 L Y P / 6-31+G(d, p)$ level of theory in NBO 3.1 as implemented in Gaussian09. ${ }^{53}$ MEP plots were calculated at by Gaussian G09 at this same level of theory and plotted with Chemcraft visualization program. ${ }^{54}$ A gaussian profile of $10 \mathrm{FWHM}$ was used to represent the band width in the calculated spectra reported. All optimized geometries and comparison between different methodologies can be found in the Supporting Information Material. SMD calculations were carried out for methanol and water using standard G09 parameters. Methanol:water 1:1 mixture parameters were obtained by using the experimental values for a 1:1 mixture of methanol:water ( 0.4:0.6 methanol:water molar fraction) for refraction index ${ }^{55}$ and surface tension ${ }^{56}$ and taking the molar fraction weighted average for the Abraham's hydrogen bond acidity and basicity, and dielectric constant, ${ }^{57}$ necessary for the SMD calculations. These parameters can be found in the supplementary information.

\section{Acknowledgements}

TCC would like to thank FAPESP (grants 2014/15962-5 and 2015/08539-1) and CAPES (finance code 001 and grant 23038.006960/2014-65). Individual fellowships are highly thanked by TCP to FAPESP (2017/20262-0) and LCT to PIBIC program (2015, project 598) and Santander International Mobility Fellowship (program 486/2015). M.A.J. thanks the Air Force Office of Scientific Research (AFOSR) under grant FA9550-18-1-1213, and acknowledges that the study was carried out using an instrument developed under (DURIP) FA9550-17-10267.

\section{Supplementary Material}

Equilibrium geometry for $[\mathrm{Cat} 1+\mathrm{H}]^{+}$and $[\mathrm{Cat} 2+\mathrm{H}]^{+}$with different protonation sites and predicted vibrational frequencies at $\mathrm{B} 3 \mathrm{LYP} / 6-311+(3 \mathrm{df}, 2 \mathrm{p})$ level of theory; $\mathrm{pK}_{\mathrm{a}}$ values for imidazolidinones different protonation sites in water; comparison between diverse calculation methodologies; SMD parameters for the 1:1 methanol:water mixture.

\section{References}

1. National Research Council (U.S.). Committee on Challenges for the Chemical Sciences in the 21st Century. Beyond the Molecular Frontier Challenges for Chemistry and Chemical Engineering; National Academies 
Press: Washington, D.C., 2003.

2. Ramsurn, H.; Gupta, R. B. ACS Sustain. Chem. Eng. 2013, 1 (7), 779-797. https://doi.org/10.1021/sc400046y

3. Muñoz-Muñoz, J. L.; García-Molina, M. del M.; Garcia-Molina, F.; Berna, J.; Garcia-Ruiz, P. A.; GarcíaMoreno, M.; Rodriguez-Lopez, J. N.; Garcia-Canovas, F. J. Mol. Catal. B Enzym. 2013, 91 (0), 17-24. https://doi.org/10.1016/i.molcatb.2013.02.003

4. Sataraddi, S. R.; Nandibewoor, S. T. Synth. React. Inorg. Met.-Org. Chem 2013, 43 (7), 809-821. https://doi.org/10.1080/15533174.2012.749905

5. Chorkendorff, I.; Niemantsverdriet, J. W. Concepts of Modern Catalysis and Kinetics; Wiley-VCH: Weinheim, 2007.

6. Lima, V. L. E. Quim. Nova 1997, 20 (6), 657-663. https://doi.org/10.1590/S0100-40421997000600015

7. Federsei, H. J. Endeavour 1994, 18 (4), 163-172. https://doi.org/10.1016/0160-9327(95)90525-Y

8. Bertelsen, S.; Jorgensen, K. A. Chem. Soc. Rev. 2009, 38 (8), 2178-2189. https://doi.org/10.1039/b903816g

9. Hajos, Z. G.; Parrish, D. R. J. Org. Chem. 1974, 39 (12), 1615-1621. https://doi.org/10.1021/jo00925a003

10. Jensen, K. L.; Dickmeiss, G.; Jiang, H.; Albrecht, Ł.; Jørgensen, K. A. Acc. Chem. Res. 2011, 45 (2), $248-264$. https://doi.org/10.1021/ar200149w

11. Erkkilä, A.; Majander, I.; Pihko, P. M. Chem. Rev. 2007, 107 (12), 5416-5470. https://doi.org/10.1021/cr068388p

12. MacMillan, D. W. C. Nature 2008, 455 (7211), 304-308.

https://doi.org/10.1038/nature07367

13. McCort-Tranchepain, I.; Petit, M.; Dalko, P. I. Organocatalysis; Wiley-VCH Verlag GmbH \& Co. KGaA, 2010. https://doi.org/10.1002/9783527628698.hgc009

14. García-Barradas, O.; Juaristi, E. Tetrahedron 1995, 51 (12), 3423-3434. https://doi.org/10.1016/0040-4020(95)00091-L

15. Capacci, A. G.; Malinowski, J. T.; McAlpine, N. J.; Kuhne, J.; MacMillan, D. W. C. Nat. Chem. 2017, 9 (11), 1073-1077. https://doi.org/10.1038/nchem.2797

16. Lee, S.; MacMillan, D. W. C. J. Am. Chem. Soc. 2007, 129 (50), 15438-15439. https://doi.org/10.1021/ja0767480

17. Beeson, T. D.; MacMillan, D. W. C. J. Am. Chem. Soc. 2005, 127 (24), 8826-8828. https://doi.org/10.1021/ja051805f

18. Austin, J. F.; Kim, S.-G.; Sinz, C. J.; Xiao, W.-J.; MacMillan, D. W. C. Proc. Natl. Acad. Sci. 2004, 101 (15), 5482-5487. https://doi.org/10.1073/pnas.0308177101

19. Kinsman, A. C.; Kerr, M. A. J. Am. Chem. Soc. 2003, 125 (46), 14120-14125. https://doi.org/10.1021/ja036191y

20. Shih, H.-W.; Vander Wal, M. N.; Grange, R. L.; MacMillan, D. W. C. J. Am. Chem. Soc. 2010, 132 (39), 13600-13603. https://doi.org/10.1021/ja106593m

21. Sacchetti, A.; Rossi, F.; Rossetti, A.; Pesa, R.; Mauri, E. Chem. Pap. 2016, 70 (4). 
https://doi.org/10.1515/chempap-2015-0232

22. Cho, H.; Jung, J.; Kim, J.; Park, S.; Kim, S. Asian J. Org. Chem. 2019, 8 (7), 1010-1016.

https://doi.org/10.1002/ajoc.201900220

23. Srivastava, V. Curr2. Organocatalysis 2016, 3 (3), 277-282.

https://doi.org/10.2174/2213337202666150729230804

24. Mountanea, O. G.; Limnios, D.; Kokotou, M. G.; Bourboula, A.; Kokotos, G. European J. Org. Chem. 2019, 2019 (10), 2010-2019.

https://doi.org/10.1002/ejoc.201801881

25. Gramage-Doria, R.; Bellini, R.; Rintjema, J.; Reek, J. N. H. ChemCatChem 2013, 5 (5), 1084-1087. https://doi.org/10.1002/cctc.201200541

26. Halland, N.; Hansen, T.; Jørgensen, K. A. Angew. Chemie Int. Ed. 2003, 42 (40), 4955-4957. https://doi.org/10.1002/anie.200352136

27. Ahrendt, K. A.; Borths, C. J.; MacMillan, D. W. C. J. Am. Chem. Soc. 2000, 122 (17), 4243-4244. https://doi.org/10.1021/ja000092s

28. Burley, J. C.; Gilmour, R.; Prior, T. J.; Day, G. M. Acta Crystallogr., Sect. C Cryst. Struct. Commun. 2008, 64 (1), o10-014.

https://doi.org/10.1107/S0108270107051396

29. Seebach, D.; Grošelj, U.; Badine, D. M.; Schweizer, W. B.; Beck, A. K. Helv. Chim. Acta 2008, 91 (11), 19992034.

https://doi.org/10.1002/hlca.200890216

30. M. Ribeiro, F. W.; Rodrigues-Oliveira, A. F.; C. Correra, T. J. Phys. Chem. A 2019, 123 (38), 8179-8187. https://doi.org/10.1021/acs.jpca.9b05065

31. Santos Fernandes, A.; Maître, P.; Carita Correra, T. J. Phys. Chem. A 2019, 123 (5), 1022-1029. https://doi.org/10.1021/acs.jpca.8b09979

32. Tripodi, G. L.; Correra, T. C.; Angolini, C. F. F.; Ferreira, B. R. V.; Maître, P.; Eberlin, M. N.; Roithová, J. European J. Org. Chem. 2019, 2019 (22), 3560-3566.

https://doi.org/10.1002/ejoc.201900171

33. Jašíková, L.; Roithová, J. Chem. - A Eur. J. 2018, 24 (14), 3374-3390.

https://doi.org/10.1002/chem.201705692

34. Fournier, J. A.; Johnson, C. J.; Wolke, C. T.; Weddle, G. H.; Wolk, A. B.; Johnson, M. A. Science. 2014, 344 (6187).

https://doi.org/10.1126/science.1253788

35. Polfer, N. C. Chem. Soc. Rev. 2011, 40 (5), 2211-2221.

https://doi.org/10.1039/c0cs00171f

36. Masson, M. A. C.; Karpfenstein, R.; de Oliveira-Silva, D.; Teuler, J.-M. M.; Archirel, P.; Maître, P.; Correra, T. C. J. Phys. Chem. B 2018, 122 (43), 9860-9868.

https://doi.org/10.1021/acs.jpcb.8b06523

37. C. Correra, T.; S. Fernandes, A.; M. Reginato, M.; C. Ducati, L.; Berden, G.; Oomens, J. Phys. Chem. Chem. Phys. 2017, 19 (35), 24330-24340.

https://doi.org/10.1039/C7CP04617K

38. Halls, M. D.; Velkovski, J.; Schlegel, H. B. Theor. Chem. Acc. 2001, 105 (6), 413-421. https://doi.org/10.1007/s002140000204

39. Rodrigues-Oliveira, A. F.; M. Ribeiro, F. W.; Cervi, G.; C. Correra, T. ACS Omega 2018, 3 (8), 9075-9085. https://doi.org/10.1021/acsomega.8b00815 
40. Patrick, A. L.; Cismesia, A. P.; Tesler, L. F.; Polfer, N. C. Int. J. Mass Spectrom. 2017, 418, $148-155$. https://doi.org/10.1016/j.ijms.2016.09.022

41. Chang, T. M.; Prell, J. S.; Warrick, E. R.; Williams, E. R. J. Am. Chem. Soc. 2012, 134 (38), 15805-15813. https://doi.org/10.1021/ja304929h

42. Warnke, S.; Seo, J.; Boschmans, J.; Sobott, F.; Scrivens, J. H.; Bleiholder, C.; Bowers, M. T.; Gewinner, S.; Schöllkopf, W.; Pagel, K.; Von Helden, G. J. Am. Chem. Soc. 2015, 137 (12), 4236-4242.

https://doi.org/10.1021/jacs.5b01338

43. Brauman, J. I.; Riveros, J. M.; Blair, L. K. J. Am. Chem. Soc. 1971, 93 (16), 3914-3916.

https://doi.org/10.1021/ja00745a016

44. Cox, R. A. Can. J. Chem. 1998, 76 (6), 649-656.

https://doi.org/10.1139/v98-012

45. Kaljurand, I.; Kütt, A.; Sooväli, L.; Rodima, T.; Mäemets, V.; Leito, I.; Koppel, I. A. J. Org. Chem. 2005, 70 (3), 1019-1028.

https://doi.org/10.1021/jo048252w

46. Wolk, A. B.; Leavitt, C. M.; Garand, E.; Johnson, M. A. Acc. Chem. Res. 2014, 47 (1), 202-210. https://doi.org/10.1021/ar400125a

47. Yang, N.; Duong, C. H.; Kelleher, P. J.; Johnson, M. A. Nat. Chem. 2019. https://doi.org/10.1038/s41557-019-0376-9

48. Frisch, M. J.; Trucks, G. W.; Schlegel, H. B.; Scuseria, G. E.; Robb, M. A.; Cheeseman, J. R.; Scalmani, G.; Barone, V.; Mennucci, B.; Petersson, G. A.; Nakatsuji, H.; Caricato, M.; Li, X.; Hratchian, H. P.; Izmaylov, A. F.; Bloino, J.; Zheng, G.; Sonnenberg, J. L.; Hada, M.; Ehara, M.; Toyota, K.; Fukuda, R.; Hasegawa, J.; Ishida, M.; Nakajima, T.; Honda, Y.; Kitao, O.; Nakai, H.; Vreven, T.; Montgomery, J. A.; Peralta, J. E.; Ogliaro, F.; Bearpark, M.; Heyd, J. J.; Brothers, E.; Kudin, K. N.; Staroverov, V. N.; Keith, T.; Kobayashi, R.; Normand, J.; Raghavachari, K.; Rendell, A.; Burant, J. C.; Iyengar, S. S.; Tomasi, J.; Cossi, M.; Rega, N.; Millam, J. M.; Klene, M.; Knox, J. E.; Cross, J. B.; Bakken, V.; Adamo, C.; Jaramillo, J.; Gomperts, R.; Stratmann, R. E.; Yazyev, O.; Austin, A. J.; Cammi, R.; Pomelli, C.; Ochterski, J. W.; Martin, R. L.; Morokuma, K.; Zakrzewski, V. G.; Voth, G. A.; Salvador, P.; Dannenberg, J. J.; Dapprich, S.; Daniels, A. D.; Farkas, Ö.; Foresman, J. B.; Ortiz, J. V.; Cioslowski, J.; Fox, D. J. Gaussian 09, Revision D.01; 2013.

49. Becke, A. D. J. Chem. Phys. 1993, 98 (2), 1372-1377.

https://doi.org/10.1063/1.464304

50. Yanai, T.; Tew, D. P.; Handy, N. C. Chem. Phys. Lett. 2004, 393 (1-3), 51-57. https://doi.org/10.1016/j.cplett.2004.06.011

51. Zhao, Y.; Truhlar, D. Theor. Chem. Acc. 2008, 120 (1-3), 215-241. https://doi.org/10.1007/s00214-0070310-x.

https://doi.org/10.1007/s00214-007-0310-x

52. Russell D. Johnson III; Johnson III, R. D. NIST Computational Chemistry Comparison and Benchmark Database, NIST Standard Reference Database Number 101 Release 14; 2006.

53. Glendening, E. D.; Reed, A. E.; Carpenter, J. E.; Weinhold, F. NBO Version 3.1. 1998.

54. Zhurko, G. A. Chemcraft - Graphical Program for Visualization of Quantum Chemistry Computations, build 536.; 2018.

55. Herráez, J. V.; Belda, R. J. Solution Chem. 2006, 35 (9), 1315-1328. https://doi.org/10.1007/s10953-006-9059-4

56. Vazquez, G.; Alvarez, E.; Navaza, J. M. J. Chem. Eng. Data 1995, 40 (3), 611-614. https://doi.org/10.1021/je00019a016 
57. Marenich, A. V.; Cramer, C. J.; Truhlar, D. G. J. Phys. Chem. B 2009, 113 (18), 6378-6396. https://doi.org/10.1021/jp810292n

This paper is an open access article distributed under the terms of the Creative Commons Attribution (CC BY) license (http://creativecommons.org/licenses/by/4.0/) 